\section{Stress evaluation of maxillary central incisor restored with different post materials: A finite element analysis}

\author{
Samarth Kumar Agarwal' ${ }^{1 *}$, Reena Mittal ${ }^{1}$, Romil Singhal ${ }^{1}$, \\ Sarah Hasan ${ }^{2}$ and Kanchan Chaukiyal ${ }^{1}$ \\ ${ }^{1}$ Department of Prosthodontics and Crown and Bridge, Kothiwal Dental College and Research \\ Centre, Moradabad, India \\ ${ }^{2}$ Darbhanga Medical College and Hospital, Darbhanga, Bihar, India
}

\section{Abstract}

Introduction: With the availability of different post systems and various studies on the strength of teeth restored with posts, the controversy as to which post systems provide better stress distribution of post and longevity of tooth has not been resolved. The purpose of this study was to compare the stress distribution of three different post materials using finite element analysis.

Materials and nethod: Three dimensional finite element models of central incisor, three posts with crown were constructed on computer with software. Posts of three different materials (Ni-Cr post, Glass fiber post, and Zirconia post)with zirconia crown were virtually generated and a force of $100 \mathrm{~N}$ was applied at an angle of 450 on the palatal surface of the crown. Von Mises stresses were evaluated on the cervical, middle and apical third of the root.

Results: The maximum stresses were seen on the cervical one-third in each post material indicating that this region is more prone to fracture in tooth restored with posts. Among the three materials tested, $\mathrm{Ni}-\mathrm{Cr}$ post showed maximum stress generation followed by Zirconia post and glass fiber post. The maximum stresses generated by the posts were $11.4 \mathrm{MPa}, 10.58 \mathrm{MPa}$ and 4.11 MPa respectively.

Conclusion: The less rigid post material like glass fiber post can be used in an endodontically treated anterior teeth.

\section{More Information}

*Address for Correspondence: Samarth Kumar Agarwal, Professor, Department of Prosthodontics and Crown and Bridge, Kothiwal Dental College and Research Centre, Moradabad, India, Email: dr.samarthagarwal@yahoo.co.in

Submitted: 08 July 2020

Approved: 20 July 2020

Published: 21 July 2020

How to cite this article: Agarwal SK, Mittal R, Singhal R, Hasan S, Chaukiyal K. Stress evaluation of maxillary central incisor restored with different post materials: A finite element analysis. J Clin Adv Dent. 2020; 4: 022-027.

\section{DOI: 10.29328/journal.jcad.1001020}

Copyright: @ 2020 Agarwal SK, et al. This is an open access article distributed under the Creative Commons Attribution License, which permits unrestricted use, distribution, and reproduction in any medium, provided the original work is properly cited.

(D) Check for updates

OPEN ACCESS

\section{Introduction}

An endodontically treated tooth requires special techniques for restoration. Usually a considerable amount of tooth structure has been lost because of caries, endodontic treatment, and placement of previous restorations. The loss of tooth structure makes retention of subsequent restoration more challenging and increases the likelihood of fracture during functional loading. If a substantial amount of coronal structure is missing, a post and core is indicated [1].

Over the years, a variety of post and core systems have been developed and different authors have classified them differently. According to mode of action, they can be Active posts or Passive post. According to shape and surface, they can be Tapered (threaded, serrated or smooth sided) or
Parallel (threaded, serrated or smooth sided). According to material, they can be Non-metallic posts like fiber posts (carbon fiber, glass fiber and quartz fiber), Metallic posts (titanium, NickelChromium etc.), Ceramic post and Composite resin post. According to manufacturing process, they can be Prefabricated or Custom post.

Although the quest for the ideal material to restore lost tooth structure continues to be a focus of modern dental research, an increased demand for clinically convenient for post and core systems to replace lost tooth structure has provided the clinician with a plethora of simplified post and core restorative options. The factors that play a role in fracture of a post and core system are the amount of tooth structure remaining, post length, post design, post stiffness, and the type of post material [2]. The post material should 
be compatible to the tooth and this can be evaluated by the stresses they generated on to the tooth structure to prevent the tooth from fracture or from the post to detach [3].

An endodontically treated tooth composed of different post and core material produces different stress level on the root, post and periodontal ligament depending on the material and the shape of the post [3].

Several methods have been used to analyze the effect of post-core system on the stress distribution in dentin. Experimental methods and the finite element method are commonly used. A 3-D finite element method is a more accurate way to analyze the stresses in a tooth [3-5].

The dental practitioner is often presented with the dilemma of selecting post materials, many of which may have deleterious effects on the tooth. The purpose of the present study is to compare the stress distributed by most widely used post materials now days, i.e., $\mathrm{Ni}-\mathrm{Cr}$, Glass fiber and Zirconia on an endodontically treated tooth.

\section{Materials and method}

Three dimensional finite element models of central incisor and the posts were constructed on a personal computer with (Intel CORE 2 duo processor with $2.1 \mathrm{GHz}, 4 \mathrm{~GB}$ of RAM, 2GB Graphic card, 1 TB Hard disk drive (HDD) and 17 inch monitor using a series of computer software programs- Materialise interactive Medical control system version 8.11(MIMICS), Hypermesh Version 13.0, Analysis System Version 12.1 (ANSYS).

The following steps were involved to construct the models:

\section{(a) Construction of the model of the of the central incisor}

The analytic model used in the study was developed from computer tomography (CT) slice images of the maxillary central incisor at a slice thickness of $1 \mathrm{~mm}$. The images were recorded in Dicom format. Using MIMICS, which is a medical modeling software used for the visualization and segmentation of CT/MRI images, the Dicom format were converted to Initial Graphics Exchange Specification (IGES) and Stereolithography (STL) formats. Small defects were also corrected, the object was smoothened and the surface quality was optimized. This led to the generation of geometric model.

\section{(b) Construction of the post}

The post model was generated using a Computer Aided Reverse Engineering (CARE). CARE creates a computer model of an object through measurements of a tangible object as it exists in the real world, using a laser-based range scanner. The posts used were parallel posts having a length of $12 \mathrm{~mm}$ and diameter of $1.5 \mathrm{~mm}$. Each point on the post had an $\mathrm{x}, \mathrm{y}$ and $\mathrm{z}$ co-ordinate locating the point in 3-D space. The collection of these points is called a point cloud. The point cloud and the detected features were then used by the CARE system to model the entire geometry of the post.

\section{Mesh generation of the model}

Finite element modeling (FEM) uses the concept of representing the object by an analytic model consisting of a finite number of elements that are interconnected at a finite number of points called nodes. This collection of nodes and elements forms the finite element mesh. These are the building blocks of the numerical representation of the model. The geometric model was converted into finite element model by using Hypermesh. ANSYS version 12.1 was the solver used to do the analysis of the present study. The model was divided into large number of elements and nodes.

Total nodes were 12656 and total elements were 63209 (Figure 1).

\section{Assigning material properties}

The material properties assigned were the Young's modulus of elasticity (E) and the Poisson's ratio (v). The corresponding elastic properties such as Young's modulus of elasticity (E) and the Poisson's ratio (v) of post, zirconia crown, glass ionomer cement, dentin, cementum, PDL, core, crown, and bone were incorporated $[2,18,19]$ (Table 1).

Three configurations were generated for each post material. In each configuration post of $8 \mathrm{~mm}$ was placed and $4 \mathrm{~mm}$ of gutta percha was left at the apical end of the tooth. A zirconia crown was generated over post to mimic clinical condition in all the models.

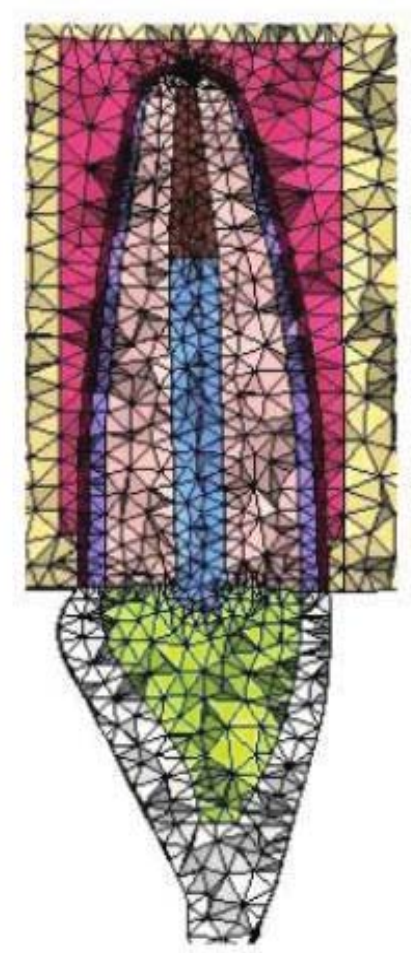

Figure 1: Mesh generated using Finite Element Modeling. 


\begin{tabular}{|c|c|c|}
\hline Material & Elastic modulus (GPa) & Poisson's ratio (v) \\
\hline Dentin $^{18}$ & 18.6 & 0.31 \\
\hline Periodontal ligament ${ }^{18}$ & 0.069 & 0.45 \\
\hline Cortical bone ${ }^{18}$ & 13.7 & 0.30 \\
\hline Trabecular bone ${ }^{18}$ & 1.37 & 0.30 \\
\hline Gutta Percha ${ }^{18}$ & 0.69 & 0.45 \\
\hline Zirconia post ${ }^{19}$ & 200 & 0.33 \\
\hline Fiber glass post ${ }^{20}$ & 53.8 & 0.30 \\
\hline Cast metal post ${ }^{21}$ & 205 & 0.33 \\
\hline Zirconia crown ${ }^{14}$ & 209.3 & 0.32 \\
\hline Glass lonomer cement ${ }^{23}$ & 4 & 0.35 \\
\hline
\end{tabular}

\section{Load application and execution of analysis}

The 3-D finite element models were loaded at an angle of $45^{0}$ to the long axis of the tooth. A load of $100 \mathrm{~N}$ was applied at the palatal surface of the crown at the cingulum.

After applying the load, a color-coded display of pattern of von Mises stress at the cervical, middle and apical third of the root was made not on cement interface. The color coding used in the study depicted red as maximum and blue as minimum and the shades in between showed variation of stresses from maximum to minimum (Figure 2).

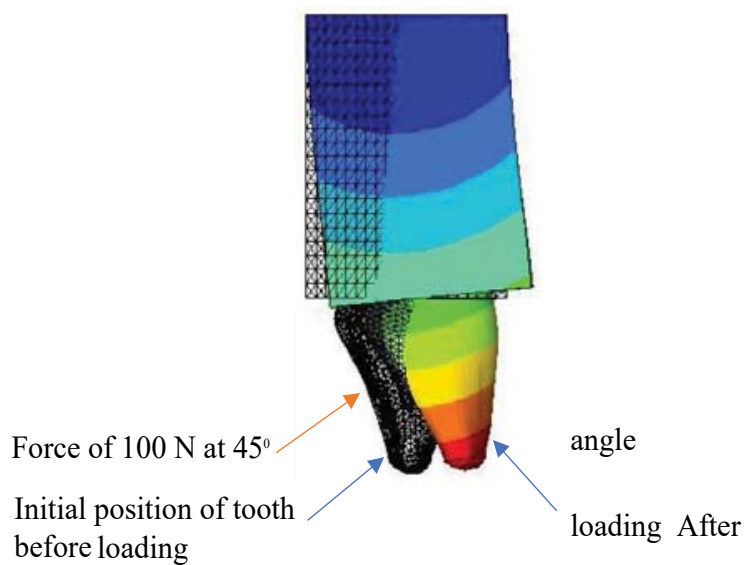

Figure 2: Cross-sectional view of displacement contour of maxillary central incisor after loading.

The data obtained from the study were evaluated to observe the effect of different post materials on the stresses they generated on the root and surrounding structures.

\section{Results}

Total of three configurations were evaluated and in each one of them the highest Von Mises stress values in the root were recorded after a load of $100 \mathrm{~N}$ was applied at angle of 450 at the palatal surface on the cingulum of the tooth (Table 2).
With a Ni-Cr post of $8 \mathrm{~mm}$ length, the maximum stress value recorded was $11.04 \mathrm{MPa}$ at the cervical $1 / 3^{\text {rd }}$ of the root. At the middle $1 / 3^{\text {rd }}$ of the root the maximum stress value recorded was $9.92 \mathrm{MPa}$ and at the apical $1 / 3^{\text {rd }}$ the maximum stress value recorded was 7.68 MPa (Figure 3) (Graph 1).

With a glass fiber post of $8 \mathrm{~mm}$ length, the maximum stress value recorded was $3.11 \mathrm{MPa}$ at the cervical $1 / 3^{\text {rd }}$ of the root. The maximum stress value recorded was $2.78 \mathrm{MPa}$ at the middle $1 / 3^{\text {rd }}$ and the maximum stress value recorded was 1.61 MPa at the apical $1 / 3^{\text {rd }}$ (Figure 4) (Graph 2).

In configuration III, with a Zirconia post of $8 \mathrm{~mm}$ length, the maximum stress value recorded was $10.58 \mathrm{MPa}$ at the cervical $1 / 3^{\text {rd }}$ of the root. At the middle $1 / 3^{\text {rd }}$ the maximum stress value recorded was 9.5 and the maximum stress value recorded at the apical 1/3 ${ }^{\text {rd }}$ was 6.2 MPa (Figure 5) (Graph 3).

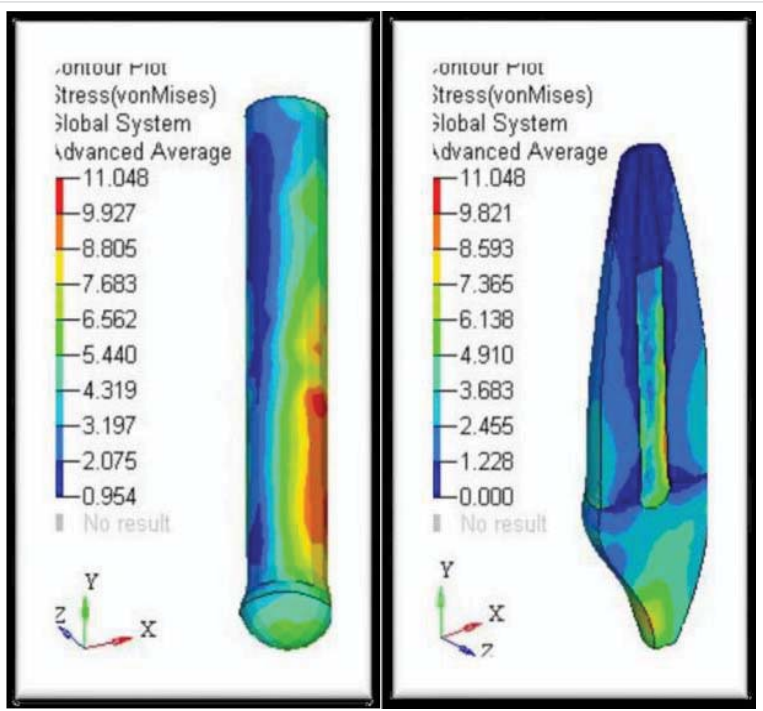

Figure 3: Von-Mises Stress Contours in Ni-Cr Post and surrounding structures.

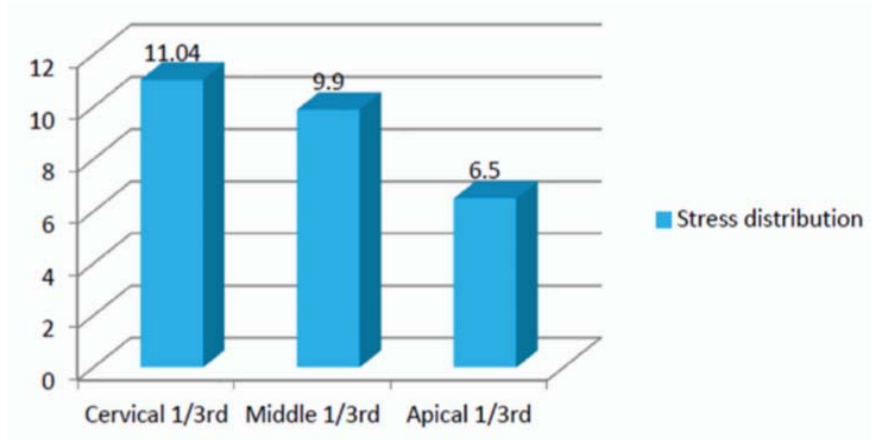

Graph 1: Stress distribution in Ni-Cr Post.

Table 2: Distribution of stresses generated by different posts.

\begin{tabular}{|c|c|c|c|c|c|c|c|}
\hline Material & $\begin{array}{l}\text { Maximum stress } \\
\text { on dentine (MPa) }\end{array}$ & $\begin{array}{c}\text { Maximum stress on } \\
\text { PDL (MPa) }\end{array}$ & $\begin{array}{l}\text { Maximum stress } \\
\text { on post }(\mathrm{MPa})\end{array}$ & $\begin{array}{c}\text { Maximum stress in } \\
\text { core }(\mathrm{MPa})\end{array}$ & $\begin{array}{l}\text { Maximum stress in } \\
\text { crown (MPa) }\end{array}$ & $\begin{array}{l}\text { Maximum stress in } \\
\text { cortical bone (MPa) }\end{array}$ & $\begin{array}{l}\text { Maximum stress in } \\
\text { spongy bone (MPa) }\end{array}$ \\
\hline $\mathrm{Ni}-\mathrm{Cr}$ & 4.80 & 0.38 & 11.4 & 8.1 & 49.74 & 36.09 & 2.18 \\
\hline Zirconia & 4.79 & 0.38 & 10.58 & 8.10 & 49.75 & 39.10 & 2.18 \\
\hline Fiber & 4.68 & 0.37 & 3.11 & 4.68 & 49.95 & 36.24 & 2.19 \\
\hline
\end{tabular}




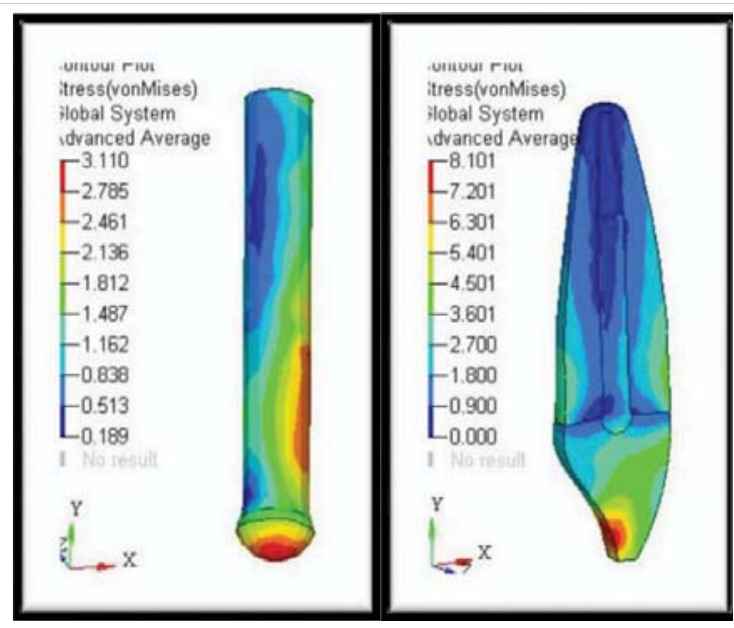

Figure 4: Von-Mises Stress Contours in Fiber Post and surrounding structures.

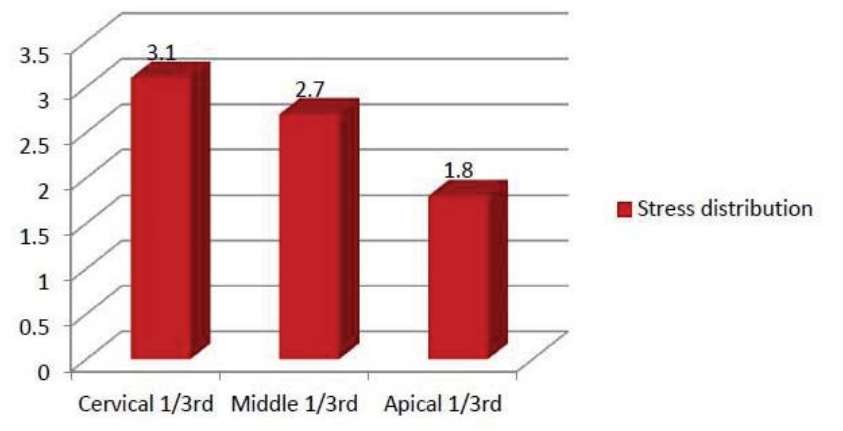

Graph 2: Stress distribution in Fiber Post.

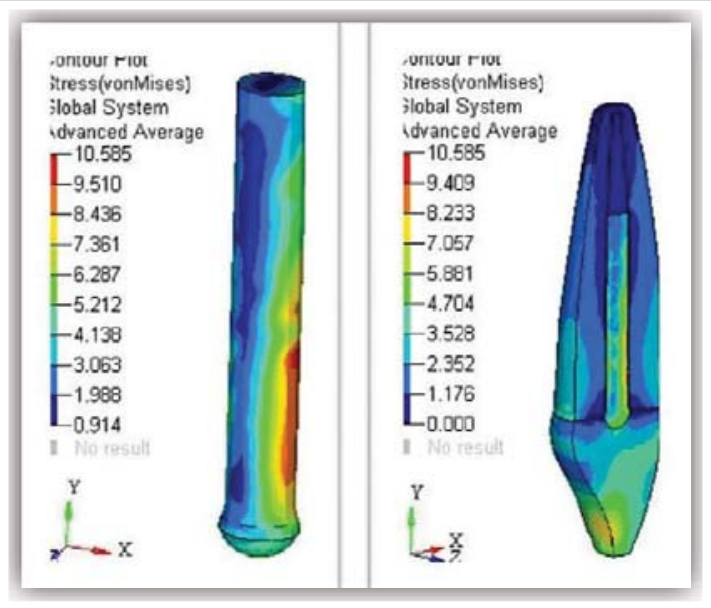

Figure 5: Von Mises Stress Contours in Zirconia Post and surrounding structures

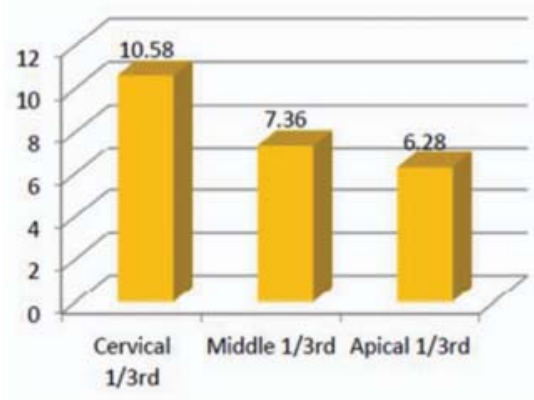

=Stress distribution

Graph 3: Stress distribution in Zirconia Post
Among the three posts tested, $\mathrm{Ni}-\mathrm{Cr}$ post showed maximum stress concentration (11.4 MPa) followed by Zirconia (10.58 $\mathrm{MPa}$ ). Least stress concentration was found in the glass fiber post which was $3.11 \mathrm{MPa}$ (Table 3).

\begin{tabular}{|c|c|c|c|}
\hline Material & $\begin{array}{l}\text { Maximum stress }(\mathrm{MPa}) \\
\text { at the cervical } 1 / 3^{\text {rd }}\end{array}$ & $\begin{array}{c}\text { Maximum stress (MPa) } \\
\text { at the middle } 1 / 3^{\text {rd }}\end{array}$ & $\begin{array}{c}\text { Maximum stress (MPa) } \\
\text { at the apical } 1 / 3^{\text {rd }}\end{array}$ \\
\hline $\mathrm{Ni}-\mathrm{Cr}$ & 11.04 & 9.9 & 6.5 \\
\hline Zirconia & 3.1 & 2.7 & 1.8 \\
\hline Fiber & 10.58 & 7.36 & 6.28 \\
\hline
\end{tabular}

\section{Discussion}

Stresses in dental structures have been studied by various techniques namely strain gauges, holography, photoelasticity, two- and three-dimensional finite element analysis and other numerical methods.

A finite element analysis is a useful tool for investigating biomechanical interactions of various designs. Tooth is a complex living tissue and its simulation in Finite element analysis is approximate. Forces on the prosthesis such as chewing and biting are transferred to the post and lead to stress in the dentin and surrounding tooth structures. Too much stress can lead to fracture of the post, loosening of the post, fracture of the tooth etc.

Metal posts made of $\mathrm{Ni}-\mathrm{Cr}$ alloy are associated with higher risk of root fracture due to the high stiffness and modulus of elasticity of the metal when compared to tooth structure, which might lead to increased stress concentration. Cast posts are advantageous as they are easy to fabricate in the mouth but since their modulus of elasticity differs from the dentin, they tend to produce undue stresses.

With the passage of time non-metal posts were developed as a result of advances in biomaterials, development in bonding and adhesive systems, and enhancement of aesthetic characteristics of dental restorations. These include composites and ceramics. Composite posts include carbon fiber, silica fiber, ribbon fiber, and light transmitting posts. Non-metal posts have superior aesthetics, biocompatible, more color stable, corrosion free, and some have similar stiffness to dental tissues thus improving stress distribution. Fiber post was selected because aesthetic posts have become popular recently. They are also well accepted because of their favorable physical properties and biocompatibility. Aesthetic fiber posts can be bonded within root canal spaces with polymer dentine-bonding agents and resin cements of similar flexibility. They effectively transmit stresses between the post and the root structure, thus reducing stress concentration and preventing fracture. The posts are composed of unidirectional glass fibers embedded in a resin matrix that strengthens the posts without compromising the modulus of elasticity. Another advantage of fiber post is that they distribute stress over a broad surface area, increasing the load threshold at 
which the dowel begins to show evidence of microfractures, but it also has some disadvantages like it requires more post space preparation and is less conservative [17].

Zirconia posts have greater strength and are more aesthetic as they do not reflect a blackish hue. They are biocompatible, corrosion resistant and strong, but their cost is a concern.

The evaluation of stress distribution patterns among Ni$\mathrm{Cr}$ post and fiber post have been investigated previously but zirconia being a relatively newer material, very few studies have been conducted to evaluate its material properties.

In this study, a force of $100 \mathrm{~N}$ was applied on the palatal surface at the cingulum at an angle of $45^{\circ}$. These loads represent the average masticatory force recorded, and were in accordance with studies by Ho, et al. [3] Joshi, et al. [6], Okamoto, et al. [7], Amarante, et al. [8], Jang, et al. [9] and Cohen, et al. [10]. The structural integrity and clinical longevity of post-and-core restored teeth are therefore strongly dependent on the state of stress created in their different regions due to occlusal loads.

Previously custom-made posts made of $\mathrm{Ni}-\mathrm{Cr}$ alloy were used. Now a days, due to high esthetic demands non-metallic posts like glass fiber and zirconia posts are frequently used. In the present study, three posts were evaluated for stress distribution and showed maximum stresses in cervical region (table no.3). Vasconcellos, et al. [13], Dejak, et al. [15], Albuquerque, et al. [16], and Amarante, etal. [8] also conducted similar studies on different post systems and found that the maximum stress concentration was at the cervical third.

While comparing the three materials for the stresses generated, it was found that $\mathrm{Ni}-\mathrm{Cr}$ posts showed highest stresses (11.4 MPa) followed by Zirconia (10.58 MPa) and least stress concentration was found in the fiber post which was $3.11 \mathrm{MPa}$. This difference in stresses was due to the difference in elastic modulus of materials. Rigid post materials showed non homogenous stress distribution while materials with elastic modulus similar to dentin showed better stress distribution [11]. Results of De Andrade, et al. [14] showed that the stress distribution in the post was found to be inversely proportional to the elastic modulus of materials (more rigid material generated 15 times higher stress). The elastic modulus of the post and cores made by CAD/CAM facility are directly proportional to the concentration of deleterious stress in its own structure.

Thus, it suggests a better prognosis of stress distribution to the luting cement and the root dentin with the use of materials with lower elastic modulus [14].

The study is significant for clinicians to help decide among the different post materials available and enlists the comparison of stress distribution properties of most commonly used post materials. Prefabricated fiber posts which are parallel in shape seem to be suitable for clinical application in endodontically treated teeth that require post restoration. Though the study evaluated stresses on three different post materials keeping their length and diameter constant, the study had certain limitations as changes in length and diameter also affects the stress distribution.

Finite element analysis has various advantages compared with studies on real models. The experiments are repeatable, there are no ethical considerations and the study designs may be modified and changed as per the requirement but there are certain limitations to this method. It is a computerized in vitro study in which clinical condition may not be completely replicated. Stress analysis is usually conducted under static loading, and the mechanical properties of materials are set as isotropic and linearly elastic, although it is not so in reality. So, the results may only be acknowledged qualitatively [22].

\section{Conclusion}

- The following conclusions were drawn from the present study:

- The stress concentration in the radicular dentin was more at the cervical third.

- Model restored with prefabricated fiber post showed more homogenous stress distribution and lesser stress concentration.

- Fiber post was found to be superior to zirconia post and $\mathrm{Ni}-\mathrm{Cr}$ metal post.

- Less rigid material showed less stress concentration.

\section{References}

1. Rosenstiel SF, Land MF, Fujimoto J. Restoration of Endodontically Treated Tooth. In: Contemporary fixed prosthodontics. 4th ed. St. Louis, Mo.: Mosby Elsevier. 2006; 336-378.

2. Peters MCRB, Poort HW, Farah JW, Craig RG. Stress analysis of a tooth restored with a post and core. J Dent Res. 1983; 62: 760-763. PubMed: https://www.ncbi.nlm.nih.gov/pubmed/6343442

3. Ho MH, Lee SY, Chen HH, Lee MC. Three-dimensional finite element analysis of the effects of posts on stress distribution in dentin. J Prosthet Dent. 1994; 72: 367-372.

PubMed: https://pubmed.ncbi.nlm.nih.gov/7990041/

4. Rubin C, Krishnamurthy $\mathrm{N}$, Capilouto $\mathrm{E}$, Yi H. Stress analysis of the human tooth using a three-dimensional finite element model. J Dent Res/ 1983; 62: 82-86. PubMed: https://pubmed.ncbi.nlm.nih. gov/6571871/

5. Ko CC, Chu CS, Chung KH, Lee MC. Effects of posts on dentin stress distribution in pulpless teeth. J Prosthet Dent. 1992; 68: 421-427. PubMed: https://pubmed.ncbi.nlm.nih.gov/1432755/

6. Joshi S, Mukherjee A, Kheur M, Mehta A. Mechanical performance of endodontically treated teeth. Finite elements in analysis and design. 2001; 37: 587-601.

7. Okamoto K, Ino T, Iwase N, Shimizu E, Suzuki M, et al. Three dimensional finite element analysis of stress distribution in composite 
resin cores with fiber posts of varying diameters. Dent Mater J. 2008; 27: 49-55.

8. Amarante MV, Pereira MVS, Darwish FAI, Camardo AF. Virtual analysis of stresses in human teeth restored with esthetic posts. Materials Research. 2008; 11: 459-463.

9. Jang JH, Park SJ, Min KS, Lee BN, Chang HS, et al. Stress behavior of cemented fiber- reinforced composite and titanium posts in the upper central incisor according to the post length: Two - dimensional finite element analysis. J Den Sci. 2012; 7: 384-389.

10. Cohen BI, Pagnillo MK, Condos S, Deutsch AS. Four different core materials measured for fracture strength in combination with five different designs of endodontic posts. J Prosthet Dent. 1996; 76: 487-495. PubMed: https://www.ncbi.nlm.nih.gov/pubmed/8933438

11. Standlee JP, Caputo AA, Hanson EC. Retention of endodontic dowels: effects of cement, dowel length, diameter, and design. J Prosthet Dent. 1978; 39: 400-405.

PubMed: https://pubmed.ncbi.nlm.nih.gov/347057/

12. Asmussen E, Peutzfeldt A, Sahafi A. Finite element analysis of stresses in endodontically treated, dowel-restored teeth. J Prosthet Dent. 2005; 94: 321-329.

PubMed: https://pubmed.ncbi.nlm.nih.gov/16198168

13. Vasconcellos WA, Cimini CA Jr., Albuquerque RC. Effect of post geometry and material on the stress distribution of restored upper central incisors using 3D finite element models. Stress distribution on incisors with posts. J of Ind Prosthodont Society. 2006; 6: 139-144.

14. De Andrade GS, Tribst JPM, Dal Piva AMD, Bottino MA, Borges ALS, et al. A study on stress distribution to cement layer and root dentin for post and cores made of CAD/CAM materials with different elasticity modulus in the absence of ferrule. J Clin Exp Dent. 2019; 11: 1-8. PubMed: https://www.ncbi.nlm.nih.gov/pmc/articles/PMC6343998/

15. Dejak B, Młotkowski A. Finite element analysis of strength and adhesion of cast posts compared to glass fiber-reinforced composite resin posts in anterior teeth. J Prosthet Dent. 2011; 105: 115-1126. PubMed: https://www.ncbi.nlm.nih.gov/pubmed/21262409

16. de Castro Albuquerque R, Polleto LT, Fontana RH, Cimini CA. Stress analysis of an upper central incisor restored with different posts. J Oral Rehabil. 2003; 30: 936-943.

PubMed: https://pubmed.ncbi.nlm.nih.gov/12950976

17. Preethi G, Kala M. Clinical evaluation of carbon fiber reinforced carbon endodontic post, glass fiber reinforced post with cast post and core: A one-year comparative clinical study. J Conserv Dent. 2008; 11: 162167.

PubMed: https://www.ncbi.nlm.nih.gov/pmc/articles/PMC2843538/

18. Krejci I, Mueller E, Lutz F. Effects of thermocycling and occlusal force on adhesive composite crowns. Journal of Dental Research. 1994; 73: 1228-1232.

PubMed: https://www.ncbi.nlm.nih.gov/pubmed/8046113

19. Christel P, Meunier A, Heller M, Torre JP, Peille CN. Mechanical properties and short-term in vivo evaluation of yttrium-oxide-partiallystabilized zirconia. J Biomed Mater Res. 1989; 23: 45-61. PubMed: https://pubmed.ncbi.nlm.nih.gov/2708404/

20. Toth JM, Wang M, Estes BT, Scifert JL, Seim III HB, et al. Polyetheretherketone as a biomaterial for spinal applications. Biomaterials. 2006; 27: 324-334.

PubMed: https://pubmed.ncbi.nIm.nih.gov/16115677/

21. Toparli M. Stress analysis in a post-restored tooth utilizing the finite element method. Journal of Oral Rehab. 2003; 30: 470-476.

22. Trivedi S. Finite element analysis: a boon to dentistry. J Oral Biol Craniofac Res. 2014; 4: 200-203.

PubMed: https://www.ncbi.nlm.nih.gov/pmc/articles/PMC4306993/

23. Li L, Wang ZY, Bai ZC, Mao Y, Gao B, et al. Three-dimensional finite element analysis of weakened roots restored with different cements in combination with titanium alloy posts. Chin Med J. 2006; 119: 305-311. PubMed: https://pubmed.ncbi.nlm.nih.gov/16537026/ 